\title{
Encourage Students with Physical Disabilities to Study Science, Mathematics, Engineering and Technology: Program ACCESS
}

\author{
Ali Mehrabian, Department of Civil Engineering and Engineering Mechanics, \\ The University of Arizona \\ John T. Olson, IBM \\ Georgia Ehlers, Graduate College, The University of Arizona \\ David Lovelock, Department of Mathematics, The University of Arizona
}

\section{Introduction}

Students with physical disabilities are underrepresented in science, mathematics, engineering, and technology (SMET). According to the National Science Foundation (Reference 1),

"a higher percentage of students with disabilities than of those without disabilities drop out of high school. Among students who were eighth graders in 1988, 10 percent of those with disabilities and 6 percent of those without disabilities had dropped out of school by 1994. Students with disabilities were less likely than those without to have received a high school diploma by 1994. Dropout and graduation rates vary by type of disability, with those with visual, hearing, or speech impairments least likely to have dropped out. Those with orthopedic impairments, learning disabilities, or "other" disabilities (including health problems, emotional problems, mental retardation, or other physical disabilities) were most likely to have dropped out".

National Education Longitudinal Study indicates that students with disabilities may be less academically prepared for college than those without disabilities: they were more likely to have taken remedial courses, less likely to have taken advanced placement courses, and had lower grade point averages and lower SAT scores (NCES 1999d). Among 1998 college freshmen, students with disabilities were more likely than those without to have earned Cs and Ds in high school. They were less likely to have met the recommended years of high school study in mathematics, biological sciences, and physical sciences; and to have spent more time between high school graduation and entry into college (Henderson 1999).

The opportunity to study, conduct research, and establish a career in these fields is a reachable goal for students regardless of physical ability.

In the Spring of 1998, a group consisting of students with physical disabilities, faculty from SMET disciplines, and staff at the University of Arizona (UA) proposed a program to the 
National Science Foundation (NSF) aimed at encouraging more students with physical disabilities to study SMET. The result of their efforts is Program ACCESS (Accessing Career Choices in Engineering and ScienceS).

Program ACCESS is a three-year project sponsored by the National Science Foundation and The University of Arizona, and is housed in the Department of Mathematics. It is a multidisciplinary program involving faculty, staff, and graduate and undergraduate students with physical disabilities from the College of Science, the College of Engineering and Mines, the Graduate College, the University Teaching Center, the Disability Resource Center, and the Department of Career Services.

The program's goal is to promote a high level of academic and professional success in SMET fields among students with physical disabilities by encouraging the removal of architectural, technological, and societal barriers that presently exist and which impede access and success in these fields. The main focus is to level the playing field and to expose more middle school, high school, and college students with physical disabilities to science, engineering, mathematics and technology.

\section{Main Successes of Program ACCESS}

1. Summer Camps for middle school students with physical disabilities

In 1999 and 2000, annual summer day camps were held at the University of Arizona Campus, with a third one scheduled for Summer 2001. Each camp is restricted to 12 middle/high school students with physical disabilities. The camp lasts for two and a half weeks. The camp's program, which occupies about six hours a day, consists of a smorgasbord of SMET topics given primarily by nationally and internationally known UA instructors. Topics have included physics, biology, botany, zoology, computer and civil engineering, mathematics, and astronomy. Several laboratory visits and field trips are also included for more hands on observations. The Camp is primarily about science and is held in a completely accessible environment to eliminate any physical barriers. The presence of trained counselors maximizes the level of exposure of the campers to the subjects, and enhances their experiences.

Our observations indicate that these camps have had lasting impact not only on the students, but also on the teaching faculty, and the parents. Based on pre- and post- student evaluations, on parent and faculty testimony, and on mentor contacts with participants, many students have developed a strong interest in science and engineering fields. For example, one of the students has decided to try to pursue a Ph.D. degree in Mathematics. These camps were also an eyeopening experience for the faculty, most of whom had previously never had to adapt their teaching techniques to students with disabilities in their classrooms. Finally, the camps increased the parents' awareness of the available resources and their confidence in their children's abilities to pursue careers in science and engineering.

Here is an excerpt from one parent's letter. 
"I have thought a lot about what it is that made your camp so wonderful for my son Justin as well as his fellow campers. To say you changed my son's life is not hyperbole. When I brought Justin to camp 2 weeks ago, I entered with a disabled child. Two weeks later, I am going home with an able child who happens to have challenges in life. He has gone from withdrawn and frustrated to friendly with other children and excited about learning. You have taught him more in 2 weeks than you will ever know.

In terms of academics, Justin would never have been exposed to higher levels of math or science, because he struggles with visual processing..........This does not mean he cannot learn, but that teaching him requires creative thinking and a commitment to helping him learn in a manner which works for him. He is forever behind his peers academically, in terms of classroom experience. You cannot imagine the pride Justin takes in knowing that he has just spent 2 weeks at a camp taught by professors, graduate students, and caring volunteers who appreciate his intelligence. Justin is rarely able to surpass his 'normal' peers in terms of life's experiences. You have changed that for him.

For me, the parent, the impact has been equally profound. For the most part, we parents of children with handicaps are 'walking wounded'. The emotional pain is severe and lasting. We worry about our children's future. The real world does not generally welcome those who are different with open arms. You have, and I thank you from the bottom of my heart. So, what is it that you have done that is so valuable? You have changed my son's perception of himself. You have shown him possibilities he never knew existed. Please don't stop what you are doing."

\section{Mentoring Program}

The mentoring program is another component of Program ACCESS. In this program college undergraduate students mentor high/middle school students, and graduate students mentor undergraduate students, all with physical disabilities. Over the past two and a half years, 14 mentors and mentees have joined the program, some of them recruited from the summer camps. Most of the mentors are majoring in science and engineering fields and have had adequate exposure to SMET courses and resources. The matching criteria are the field of study, type of disability and personality.

A mentor acts as a "buddy who has been through it". In addition to serving as role models, mentors constantly encourage mentees by asking them critical questions and challenging them regarding their overall academic and professional goals, performance, and directions in life. Mentors and mentees maintain contact throughout the years via email, phone calls and occasional one-on-one meetings.

Both mentees and mentors acknowledge that the experiences have been very encouraging and illuminating. Being able to rely on a friend and a role model with a disability that has been 
through a similar situation, means that the mentee does not feel alone in the academic challenges and on life's journey.

\section{Encouragement Grants}

Each year, Program ACCESS allocates money to fund 10 middle/high school teachers for projects, up to $\$ 2000$ each. These projects are selected based on proposals submitted by teachers. The successful projects encourage participation of students with disabilities in science and engineering related activities.

Prior to the proposal submission, Program ACCESS offers a 3-hour grant writing workshop to middle/high school teachers. These workshops are aimed at teaching the teachers how to develop a successful program and to introduce them to the available resources.

An example of these funded projects was building an accessible walkway for students with physical disabilities for observations of a wetland in one of the regional high schools. The project was very successful and received publicity in one of the local newspapers as well as a local TV station.

\section{Lab Assessment and Design by Architecture Students}

Assessing UA labs is a joint project between Program ACCESS and the University of Arizona College of Architecture. Each year 40 sophomore architecture students visit and survey laboratories that lack adequate accessibility options and make recommendation on retrofitting and transforming them into "barrier free" laboratories. These visits are part of a project for a studio class required to be taken by all architecture students. The objectives of these experiences are to train and expose the future architects to the accessibility issues and to increase their awareness of the issues involving designing laboratories for students with disabilities. These projects are also educational to the University and its surrounding community in general.

Students are divided into three groups, each group accompanied by SMET students with physical disabilities who are actual and potential users of the laboratories. Each group visits a separate laboratory, makes observations on the accessibility issues, talks to the students with disabilities, and takes pictures and measurements as required. The issues to be addressed usually range from inadequate accessibility of the laboratory equipment to the space design and circulation of the laboratories from the point of view of both function and form. Students then return to the studio and work on the problems and develop creative solutions.

The results of the survey and the recommended design solutions are presented in the form of final reports and displayed in a public, community setting. These reports and project displays are visited by campus facility planners, department heads, students with disabilities, participants in the survey, local designers specializing in universal design, and science and engineering teachers from area middle and high schools. 
In the past 3 years, 10 laboratories, 120 architecture students, and several other key people involved with the facility planning have been impacted by this successful component of Program ACCESS. The results are also disseminated to the public via Program ACCESS web site at http://w3.arizona.edu/ access.

\section{Summary}

The goal of the Program ACCESS three-year project is to create a model program that targets students in Arizona at all levels — from middle school through graduate school—who are physically disabled, in order to increase the proportion following SMET curricula. Program ACCESS promotes opportunities for SMET middle school, high school, and university students with physical disabilities to achieve a high level of success, both academically and professionally, through the removal of architectural, technological, and societal barriers that presently exist.

This paper concentrates on the main successes of Program ACCESS, which consist of four interrelated components.

1. Summer Camps. The objective of this component is to increase the proportion of middle school students with physical disabilities throughout Arizona who will pursue SMET subjects for college preparation when they become high school students and later on, when they become undergraduate and graduate college students. This is a two and a half-week long summer camp held at UA for 12 middle school students with physical disabilities. Topics are drawn from Biology, Chemistry, Computer Science, Engineering, Mathematics, and Physics.

2. Mentoring Program. This establishes a mentoring and role model system between SMET middle and high school students, college students, and SMET professionals in industry and in education, all with physical disabilities. At the UA, SMET graduate students with physical disabilities mentor SMET undergraduates and undergraduate students mentor middle/high school students.

3. Encouragement Grants. These grants encourage the participation of middle/high school teachers in the design of projects to promote continued study in SMET among students with physical disabilities. Program ACCESS awarded 15 grants, of \$2000 each, through a competitive process to science/math teachers who are encouraged to attend a grant writing/program development workshop.

4. Lab Assessment and Design by Architecture Students. The objective of this component of Program ACCESS is to assess existing SMET laboratories at the University of Arizona (UA) with a view to transforming them into barrier free environments allowing full access to all equipment contained therein. Through collaboration with the School of Architecture, Program ACCESS performed assessments of UA SMET laboratory facilities, and specified changes that would transform each laboratory surveyed into a barrier free environment. 
Bibliography

1. URL http://www.nsf.gov/sbe/srs/nsf00327/access/c1/cl.htm

2. Students with Disabilities in Post-secondary Education: A Profile of Preparation, Participation, and Outcomes. By Laura Horn and Jennifer Berktold. NCES 1999-187. Washington, DC: U.S. Department of Education. 1999d.

3. Henderson, Cathy. 1999. Update on College Freshmen with Disabilities. Washington, DC: American Council on Education/HEATH Resource Center.

\begin{abstract}
ALI MEHRABIAN
Ali Mehrabian is a Doctoral Candidate (ABD) in Civil Engineering and Engineering Mechanics at the University of Arizona, and a co-PI of Program ACCESS. He received his B.S. and M.S. in Civil Engineering from San Jose State University in San Jose, California.

JOHN T. OLSON

John T. Olson received his Ph.D. in Electrical and Computer Engineering from the University of Arizona in May 2000. Currently, he is a Staff Development Engineer/Scientist in the Reliability Availability Serviceability (RAS) department of the Removable Media Storage Solutions (RMSS) division of IBM. He is also a co-PI of Program ACCESS.
\end{abstract}

\title{
GEORGIA EHLERS
}

Georgia Ehlers is Coordinator of Grant and Scholarship Development for the University of Arizona Graduate College. She has a M.S. in Community and Regional Planning from the University of Texas at Austin and worked in city planning in Ohio and Texas for twenty years. She is a co-principal investigator for Project ACCESS, working on the lab accessibility project and the summer camp.

\section{DAVID LOVELOCK}

David Lovelock is Professor of Mathematics at the University of Arizona, and PI of Program ACCESS. 